\title{
Physical, Mechanical and Thermal Properties of Sugar Palm Yarn Fibre Loading on Reinforced Unsaturated Polyester Composites
}

\author{
Mohd Nurazzi Norizan, ${ }^{1 *}$ Khalina Abdan,,${ }^{1,2}$ Mohd Sapuan Salit ${ }^{1,2}$ \\ and Rahmah Mohamed ${ }^{3}$ \\ ${ }^{1}$ Faculty of Engineering, Universiti Putra Malaysia, \\ 43400 UPM Serdang, Selangor, Malaysia \\ ${ }^{2}$ Institute of Tropical Forestry and Forest Products (INTROP), \\ Universiti Putra Malaysia, 43400 UPM Serdang, Selangor, Malaysia \\ ${ }^{3}$ Faculty of Applied Sciences, Universiti Teknologi MARA (UiTM), \\ 40450 Shah Alam, Selangor, Malaysia
}

*Corresponding author: zaidharithah66@yahoo.com

Published online: 15 November 2017

To cite this article: Norizan, M. N. et al. (2017). Physical, mechanical and thermal properties of sugar palm yarn fibre loading on reinforced unsaturated polyester composites. J. Phys. Sci., 28(3), 115-136, https://doi.org/10.21315/jps2017.28.3.8

To link to this article: https://doi.org/10.21315/jps2017.28.3.8

\begin{abstract}
This study was conducted to evaluate the performance of sugar palm yarn fibre reinforced unsaturated polyester composites. The effect of sugar palm fibre yarn loading on the physical (density, voids and water absorption analysis), mechanical (tensile, flexural and impact analysis) and thermal (TGA) properties of composites were investigated. Composites with different sugar palm fibre yarn loadings (10, 20, 30, 40 and $50 \mathrm{wt} \%$ ) were prepared using the hand layup method. Results showed that the determination of composite density indicates void determination, much of which is related to an increase in fibre loadings. Determination of water absorption at various loadings revealed that the percentage of water absorption increases as fibre loading increases. Water absorption reached equilibrium absorption on day 12. Tensile strength, tensile modulus, flexural strength and flexural modulus show increments up to $30 \mathrm{wt} \%$ of fibre loadings. Elongation at break showed an increasing trend up to $50 \mathrm{wt} \%$ of fibre loading. Furthermore, impact strength of the $40 \mathrm{wt} \%$ fibre loadings sample showed the highest impact energy in resisting the fractures among all samples. The addition of sugar palm decreases the thermal stability of the entire system.
\end{abstract}

Keywords: Sugar palm, yarn, unsaturated polyester, properties of sugar palm, fibre loading 


\section{INTRODUCTION}

Recently, an increase in ecological awareness has caused a paradigm shift towards the utilisation of renewable resources and the production of environmentally friendly materials. Therefore, natural fibres such as those from sugar palm, banana, pineapple leaf, kenaf, cotton and jute have attracted the attention of academia and industry for their potential widespread applications. ${ }^{1}$ Enthusiasm has grown for natural fibres as reinforcement materials due to their relative abundance, renewability, low density, significant strength and stiffness enhancement, environmental friendliness, and ability to substitute for petroleum-based synthetic glass and carbon fibres. Koronis et al. listed different kinds of natural fibres (e.g., flax, hemp, jute, kenaf and so on) together with their physical and mechanical properties. $^{2}$

According to Vilay et al., by taking into consideration of the natural fibres' low density, their specific strength and stiffness are comparable to those of glass fibre. ${ }^{3}$ However, natural fibres' major drawback is their highly hydrophilic nature, which leads to inherent incompatibility and interfacial debonding effects with the hydrophobic thermoplastic and thermosetting matrices. ${ }^{4}$ Hence, several studies on natural fibres' use as reinforcement in polymeric composites have shown that the sensitivity of certain physical, mechanical and thermal properties towards moisture absorption maybe minimised or prevented with the use of physical and chemical modifications of the fibres' surface and structure. ${ }^{5-7}$

Sugar palm fibre is a natural fibre with great potential sourced from Arengga pinnata trees. Palm sap tapping was historically popular, as the sap was commonly used as the base material for making traditional sugar blocks, locally known as gula kabung or gula enau. ${ }^{8,9}$ Its fruits may also be processed for making pickles, juices and desserts, and are usually canned for the food industry. The most important part after its palm sugar and fruits is its black fibre called ijuk. This black fibre has many applications and uses, such as the manufacturing of brooms, paint brushes, septic tank base filters, clear water filters, door mates, carpets and ropes for sea cordage. ${ }^{10}$ According to Ishak et al., sugar palm fibre usage has three major advantages. ${ }^{11}$ It offers high tensile strength (similar to the strength of coir, kenaf, bamboo and hemp fibres within the range between 138.7 MPa to $270 \mathrm{MPa}$ ) lasts long before degradation; it is a fairly durable fibrous material with good resistance to sea water; and finally, it is less affected by heat and moisture damage as compared to coir fibre. Concerning the use of sugar palm fibre as a reinforcement material in composites, a number of studies had been carried out on the properties of sugar palm fibre reinforced composites. It has been shown that sugar palm fibres have excellent composite potential, not unlike other natural fibres such as kenaf, jute, oil palm, sugarcane bagasse, pineapple leaf, and banana pseudo stem fibres. ${ }^{12-26}$ 
In natural fibre-reinforced polymer composite applications, the fibres orientation plays a significant role in determining the mechanical properties of the composites with respect to the orientation of the applied load. ${ }^{27}$ Applied fibre alignment is another major factor influencing such composites' properties. The best tensile, flexural, and impact properties are found in properly-aligned natural fibre composites. Fibre alignment choice is much more significant with higher fibre contents. Residual stress in thermoplastic matrix composites exists due to internal pressure gradients; non-uniform temperature profiles; polymer chain alignment; and differences in fibre and matrix thermal expansion coefficients. All these factors may reduce composite strength. ${ }^{28}$ Studies done by Brahim and Cheikh on alfa reinforced polyester composites with different fibre orientation $\left(0^{\circ}, 10^{\circ}\right.$, $30^{\circ}, 45^{\circ}$ and $90^{\circ}$ ) found that the tensile strength and modulus decreased with an increase in angle from $150 \mathrm{MPa}$ down to $18 \mathrm{MPa}$, and $122.3 \mathrm{GPa}$ down to $5 \mathrm{GPa}$, respectively. ${ }^{29}$ The decrease in modulus for the $10^{\circ}$ orientation was found to be less than $7 \%$ when compared to the $0^{\circ}$ (longitudinal direction), and was tremendously decreased for increasing angles up to the $90^{\circ}$ (transverse direction). However, most researchers have focused on random orientation either in the form of short or long fibres, and only a few researchers have examined the yarn structure of fibres used as reinforcement. In industrial practice, there are two types of twisted or yarn fibre structures in terms of fibre length used: continuous long fibre (filament) and the short fibre (staple) system. Pan explained the basis role of twist in continuous long fibre as mainly to produce a coherent structure that cannot readily be disintegrated by lateral actions. ${ }^{30}$

The twist structure is therefore not essential to adding tensile strength to the structure. It may in fact lower yarn strength because of the induction of fibre obliquity. However, yarn twist in most short fibre yarns has the primary function of causing the fibres to be bound together by friction in forming a stronger yarn. The twist is hence fundamental to providing a certain minimum coherence between fibres, without which a short fibre yarn with significant tensile strength cannot be made. This coherence is dependent on the frictional forces brought into play by the lateral pressures between fibres arising from the applications of a tensile stress along the yarn axis. ${ }^{30}$

Pan also made the assumption of stress transfer towards the yarn composites system in which when a fibre breaks, the load it is carrying is then equally shared among the surviving fibres. ${ }^{30}$ The effects of stress concentration and dynamic wave propagation may thus be ignored. ${ }^{30}$ Additionally, Monego and Becker explained the fragmentation mechanisms of stress distribution within the composites of the yarn fibres. ${ }^{31}$ It was observed during the fracture process of both composites and yarns, that the constituent fibres broke repeatedly with increasing strain of the structure before overall material failure. This phenomenon indicates that quite 
contrary to commonplace assumptions, a broken fibre can again build up tension, carry subsequent load, break again into even shorter segments, and still contribute to overall system strength. ${ }^{32}$

Generally, increasing fibre loading on the composites will result in a significant increase of composite stiffness, as tensile and impact strengths are increased through the addition of natural fibres. However, the increase of fibre loading increases composite odour as well as water uptake. ${ }^{1,33}$ Recently, several studies have been conducted to determine the natural fibre loading optimum value within the composites in order to improve their mechanical properties. Per Shalwan and Yousif, there is not yet a fibre volume faction and natural fibre loading universal value for which an optimum tensile strength could be achieved..$^{27}$ In other words, for each fibre type, there is a type-specific optimum loading for exhibiting good tensile strength. This may be related to the nature of the natural fibres and their inherent strength, interfacial adhesion, and physical properties characteristics. ${ }^{27}$ Furthermore, several researchers have commonly agreed that at a high volume fraction (above 50\%), fibres tend to form aggregations which result in the weakening of the interfacial area and debonding between the fibres and matric..$^{29,33-36}$

Therefore, the objective of this study includes investigating the effects of sugar palm fibre yarn loading on the physical, mechanical and thermal properties of reinforced unsaturated polyester composites.

\section{EXPERIMENTAL}

\subsection{Materials and Methods}

Sugar palm fibre (L/D ratio 66.67) was obtained from Kampung Kuala Jempol, Negeri Sembilan, Malaysia. The chemical constituents of sugar palm fibre are shown in Table 1 as determined using an in-house method of the Malaysia Agricultural Research and Development Institute (MARDI). Unsaturated polyester resin (UPE) (RTM grade, $40 \%$ of styrene content, density of $1.025 \mathrm{~g} \mathrm{~cm}^{-3}$ ); methyl ethyl ketone peroxide (MEKP) (Butanox-M50) as curing initiator; and cobalt as reaction accelerator were supplied by CCP Composites Resins Malaysia Sdn. Bhd.

Table 1: Chemical constituents of sugar palm fibre.

\begin{tabular}{lc}
\hline Chemical constituents & Composition (\%) \\
\hline Cellulose & 47.74 \\
Hemicellulose & 5.96 \\
Lignin & 37.68 \\
Others & 8.62 \\
\hline
\end{tabular}




\subsection{Yarning of Sugar Palm Fibre}

A manual hand spinning machine from SDL ATLAS was used to make a sugar palm fibre yarn with 2500 tex (Figure 1(a)).

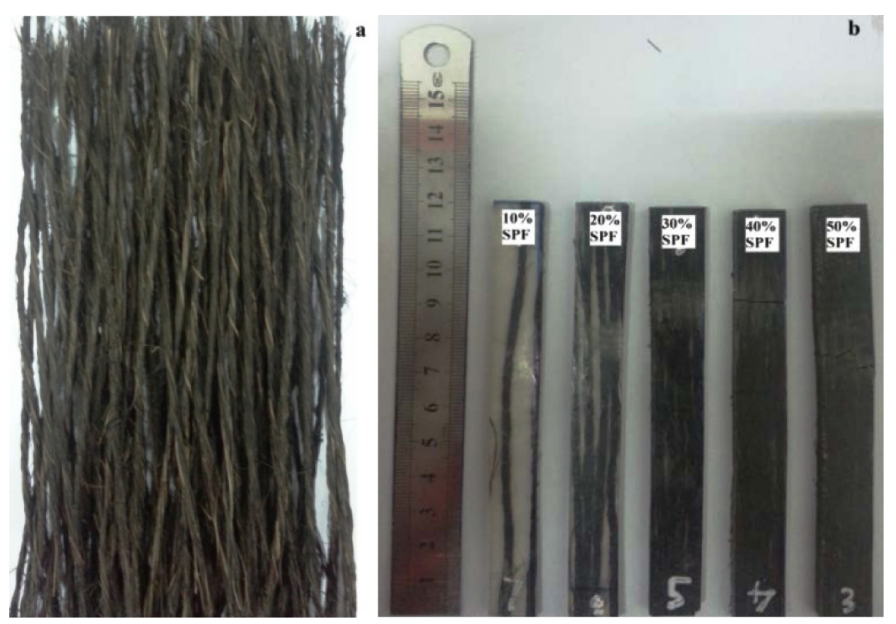

Figure 1: Sugar palm fibre yarn fibre (a), and sugar palm yarn fibre reinforced unsaturated polyester composite (b).

\subsection{Preparation of Composite}

The sugar palm fibre yarn was horizontally placed in the closed steel mould with dimensions $160 \mathrm{~mm} \times 120 \mathrm{~mm} \times 3 \mathrm{~mm}$. Initially, the $1 \%$ of MEKP as the initiator was mixed well with UPE resin, followed by mixing it with $0.2 \%$ of cobalt. Then, the mixed resin was poured over the fibre and compressed using hot press machine with $70^{\circ} \mathrm{C}$ and 80 bar for $30 \mathrm{~min}$. A mould was pre-sprayed with silicon mould release agent to avoid any stacking with the composites.

\subsection{Characterisations}

\subsubsection{Physical testing}

The densities of the composites were determined using Electronic Densimeter Alfa Mirage. The theoretical densities of these composites were calculated per ASTM as in Equation 1:

$$
T_{d}=\frac{100}{\frac{R}{D}+\frac{r_{1}}{d_{1}}}
$$


where $\mathrm{T}_{\mathrm{d}}$ is the theoretical density, $R$ and $r_{l}$ referred to resin and sugar palm fibre wt $\%$ respectively. $D$ and $d_{l}$ referred to densities of resin and sugar palm. Values from the theoretical and experimental are compared in Table 2.

The theoretical void content is calculated using Equation 2 and the void content is tabulated in Table $2::^{37}$

$$
\mathrm{V}=100\left(\mathrm{~T}_{\mathrm{d}}-\mathrm{M}_{\mathrm{d}}\right) / \mathrm{T}_{\mathrm{d}}
$$

where $\mathrm{V}$ is a void content, $T_{d}$ is a theoretical composite density, and $\mathrm{M}_{\mathrm{d}}$ is an experimental composite density.

The effect of water absorption on composites was calculated using Equation 3 according to ASTM D570. Specimens with dimensions of $10 \mathrm{~mm} \times 10 \mathrm{~mm} \times 3 \mathrm{~mm}$ were immersed for $24 \mathrm{~h}$ intervals until constant weight was obtained:

$$
\text { Water absorption } \left.=\left[\left(\mathrm{W}_{1}-\mathrm{W}_{0}\right) / \mathrm{W}_{0}\right)\right] \times 100
$$

where $\mathrm{W}_{1}$ and $\mathrm{W}_{2}$ are the average weights of the specimens before and after immersion in distilled water, respectively.

\subsubsection{Mechanical testing}

The tensile test was performed using Instron 3365 test machine according to ASTM D3039. The dimensions of the samples were $120 \mathrm{~mm} \times 15 \mathrm{~mm} \times 3 \mathrm{~mm}$. The gauge length was $60 \mathrm{~mm}$, with a crosshead speed of $5 \mathrm{~mm} \mathrm{~min}^{-1}$ applied for the test. The flexural test was performed using the three-point bending method using Instron 3365 test machine according to ASTM D790. The dimensions of the samples were $127 \mathrm{~mm} \times 13 \mathrm{~mm} \times 3 \mathrm{~mm}$. The crosshead speed was set at $5 \mathrm{~mm} \mathrm{~min}^{-1}$. The izod impact test was performed using Instron CEAST 9050 testing machine with the capacity of pendulum $5.5 \mathrm{~J}$ according to ASTM D256. The dimensions of the samples were $65 \mathrm{~mm} \times 10 \mathrm{~mm} \times 3 \mathrm{~mm}$. For each sample, 10 repetitions were performed and the average then calculated.

\subsubsection{Thermal testing}

Thermogravimetric analysis (TGA) was performed via a Perkin Elmer Pyris 6 TGA. TGA analysis was conducted under ramp mode from $30^{\circ} \mathrm{C}$ to $600^{\circ} \mathrm{C}$ under a nitrogen atmosphere at a flow rate of $50 \mathrm{ml} \mathrm{min}^{-1}$. The heating rate utilised was $20^{\circ} \mathrm{C} \mathrm{min}^{-1}$. 


\section{RESULTS AND DISCUSSION}

\subsection{Physical Characterisations}

\subsubsection{Density and void determination}

Table 2 shows the density of the sugar palm yarn fibre reinforced polyester composites with varying fibre loadings. The experimental density of the composites decreased from $1.212 \mathrm{~g} \mathrm{~cm}^{-3}$ to $1.120 \mathrm{~g} \mathrm{~cm}^{-3}$ within $0 \mathrm{wt} \%$ to $50 \mathrm{wt} \%$ of fibre loading range. The density of composites decreased with the fibre loading increase. This may be due to sugar palm fibres' lower density $\left(1.053 \mathrm{~g} \mathrm{~cm}^{-3}\right)$ compared to the polyester resin $\left(1.212 \mathrm{~g} \mathrm{~cm}^{-3}\right)$.

Table 2: Variation of density of sugar palm yarn fibre reinforced polyester composites.

\begin{tabular}{cccc}
\hline $\begin{array}{c}\text { Fibre loading } \\
(\mathrm{wt} \%)\end{array}$ & $\begin{array}{c}\text { Experimental density } \\
\left(\mathrm{g} \mathrm{cm}^{-3}\right)\end{array}$ & $\begin{array}{c}\text { Theoretical density } \\
\left(\mathrm{g} \mathrm{cm}^{-3}\right)\end{array}$ & $\begin{array}{c}\text { Theoretical void content } \\
(\text { vol\% })\end{array}$ \\
\hline 0 & 1.212 & $1.1-1.15$ & 0 \\
10 & 1.207 & 1.194 & 0 \\
20 & 1.206 & 1.177 & 0 \\
30 & 1.157 & 1.159 & 0.173 \\
40 & 1.137 & 1.143 & 0.525 \\
50 & 1.120 & 1.127 & 0.621 \\
\hline
\end{tabular}

The results show that sugar palm yarn reinforcement decreases the value of experimental densities. However, as a comparison of its experimental and theoretical density values, efficient packing and greater extent interfacial adhesion may be reasons for higher experimental composites densities, leading to a zero theoretical value for the voids. For pure UPE, density varies from the theoretical value due to moulding temperature, moulding time, and thereby the extent of inherent crosslinking. In the case of $30 \mathrm{wt} \%$ to $50 \mathrm{wt} \%$ of yarn loading, the void content increases as the fibre loading increases. This may be due to entrapped moisture between the fibres, and the increased hemicellulose and cellulose presence categorised in the hydroxyl group and which tend to attract water molecules.

Composites at higher fibre loadings may also exhibit voids. Voids in polymer composites are largely attributed to the processing effect and may occur during the curing process of the resin, residual solvents, or from entrapped air. Besides the usual shrinkage during the resins' curing, cooling rate plays an important role in void formation. ${ }^{37-39}$ 


\subsubsection{Water absorption determination}

Moisture absorption results for sugar palm fibre yarn reinforced unsaturated polyester composites are shown in Figure 2. It can be seen that the composites' water absorption levels increase correspondingly with soaking time. As the fibre content increases, the percentage of water absorption also increases. Due to hydrophilic nature of sugar palm fibre, increased fibre loading is known to increase the number of hydroxyl groups present in the cellulose and lignin structures. ${ }^{40}$ This hydroxyl groups can hold water molecules, via hydrogen bonding, within the fibre cell wall. Thus, as the sugar palm fibre yarn increases, the composites' water absorption increases due to the increase in hydroxyl groups in the composites. ${ }^{41}$ However, water absorption reached its plateau on day 12 onwards, indicating that they became equilibrated with water immersion. ${ }^{22}$

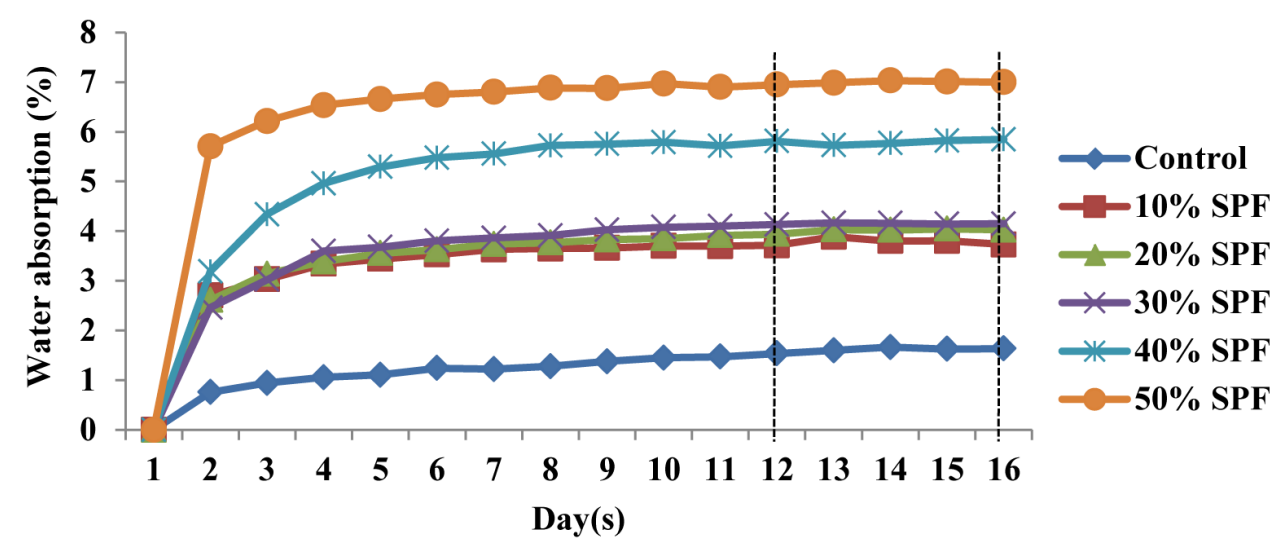

Figure 2: Effect of sugar palm yarn loading on water absorption.

\subsection{Mechanical Characterisations}

\subsubsection{Tensile properties}

The tensile properties of sugar palm fibre yarn reinforced unsaturated polyester composites are presented in Table 3.

The fibre was used as reinforcement in yarn form and is applied parallel to the tensile stress direction (longitudinal). This meant that any stress applied is uniaxial, behaving as an isotropic material. Initial tensile strengths for the 10 and $20 \mathrm{wt} \%$ fibre loading are low, as the inherent fibres were unable to equally distribute stress along its fibre as the matrix taking up the stress within the composite. However, tensile strength and modulus value of composites increase after the addition of 
fibre loadings up to $30 \mathrm{wt} \%$. Upon reaching $30 \mathrm{wt} \%$ loading, the stress can then be transferred successfully and uniformly along the fibre yarns. Further increase in the fibre loading however results in properties decrement. Similar findings were reported by Sreekumar et al., where they found that, the addition of sisal leaf fibre reinforced polyester composites up to $43 \mathrm{vol} \%$ increases the tensile strength, tensile modulus, flexural strength and flexural modulus. ${ }^{42}$ Tensile strength, tensile modulus, flexural strength and flexural modulus decreased after the addition of sisal leaf fibre after the $50 \mathrm{vol} \%$. At lower fibre loadings, fibre dispersion is quite poor and stress transfer will not occur properly. At higher fibre loadings, the tendency of fibre-fibre interaction is high. This leads to poor fibres wetting. In such systems, crack initiation and propagation will occur more easily at higher loadings. ${ }^{42}$

Table 3: Effect of yarn sugar palm loading on tensile properties.

\begin{tabular}{cccc}
\hline \multirow{2}{*}{$\begin{array}{c}\text { Sugar palm yarn loading } \\
(\text { wt } \%)\end{array}$} & \multicolumn{3}{c}{ Tensile properties } \\
\cline { 2 - 4 } & Strength (MPa) & Modulus $(\mathrm{GPa})$ & Elongation at break (\%) \\
\hline 0 & $44.40(2.62)$ & $3.54(0.11)$ & $2.15(0.27)$ \\
10 & $19.12(2.16)$ & $3.16(0.23)$ & $0.80(0.14)$ \\
20 & $29.30(1.49)$ & $3.28(0.11)$ & $1.13(0.11)$ \\
30 & $40.91(1.57)$ & $4.43(0.08)$ & $1.39(0.07)$ \\
40 & $38.00(1.94)$ & $4.01(0.09)$ & $1.65(0.12)$ \\
50 & $36.73(1.26)$ & $3.90(0.14)$ & $1.73(0.16)$ \\
\hline
\end{tabular}

Notes: Figures in parentheses refer to standard deviation

However, unsaturated polyester composites demonstrated higher tensile strength before fibre loading addition from $10 \mathrm{wt} \%$ to $50 \mathrm{wt} \%$; this is due to little stress concentration between appearance. This is strongly related to unsaturated polyester matrix dilution, and the introduction of flaws at the fibre ends, where high stress concentration occurs as a result of interfacial bond between sugar palm fibres as imparted by the inbuilt cellulose microfibrils.

Another factor contributing to the tensile strength deterioration after $30 \mathrm{wt} \%$ fibre loading is the de-wetting effect. ${ }^{43}$ Higher sugar palm fibre loading tends to promote more fibre-fibre interaction as opposed to fibre-matrix interaction. Therefore, the wettability of sugar palm fibre yarn by the unsaturated polyester matrix was significantly reduced, thus resulted in poor stress transfer upon application of stress concentrations. With an increase in fibre loadings, incompatibility in the interfacial region between sugar palm fibre and unsaturated polyester increased. This is due to highly hydrophilic nature of sugar palm and the hydrophobic nature of unsaturated polyester matrix. ${ }^{41}$ 
The tensile modulus corresponds to stiffness, i.e., the higher the tensile modulus value, the stiffer the composites. According to Supri and Ismail, the tensile modulus or stiffness of a composite is also dependent on the stiffness of the fibre itself. ${ }^{44}$ In this study, the incorporation of sugar palm fibre yarn increases the composites stiffness, as shown by the higher tensile modulus, which gradually increased with sugar palm yarn loading accretions. The presence of the sugar palm yarn restricts the unsaturated polyester matrix from moving freely, thereby increasing the rigidity of the composite..$^{45}$ The elongation at break of sugar palm fibre yarn reinforced unsaturated polyester composites with different fibre loadings are also affected. The elongation at break for composites at $50 \mathrm{wt} \%$ is the highest as compared to 10 , 20,30 and $40 \mathrm{wt} \%$ of fibre loadings. This is due to the rigidity of sugar palm fibers contributing to the plasticity of the composites system (the elongation at break of sugar palm is $7.83 \%$ while UPE is $2.15 \%){ }^{46}$

From the Rule of Mixture (ROM) theory, an approximate composite modulus can be obtained from a modified ROM equation as follows:

$$
\mathrm{E}_{\mathrm{c}}=\eta_{0} \mathrm{E}_{\mathrm{f}} \mathrm{V}_{\mathrm{f}}+\mathrm{E}_{\mathrm{m}} \mathrm{V}_{\mathrm{m}}
$$

where $\eta_{0}$ refers to as the Krenchel factor or efficiency factor, and the value differs according to the fibre orientation. $E_{f}$ and $E_{m}$ refer to modulus of fibre and matrix respectively, while $V_{f}$ and $V_{m}$ refer to volume fraction of fibre and matrix respectively. According to Aziz et al., the $\eta_{0}$ for unidirectional fibre is equal to 1 and $\eta_{0}$ for randomly oriented fibre is equal to $0.25 .{ }^{47}$

Figure 3 shows that there are differences between the theoretical and experimental values of the modulus. The experimental modulus value obtained for the $20 \mathrm{wt} \%$ yarn loading is less than its theoretical value. The lowered differences could be due to the fibre orientation during the composites' preparation. The action of manually lining up the fibres in a straight manner is almost impossible due to the nature of natural fibre. Consequently, sugar palm fibres used were in coil form. Fibres were not perfectly aligned, causing alignment problems during the yarning process and composite manufacturing. Besides that, deviation in fibre angles amounts to a maximum $5^{\circ}-10^{\circ}$ instead of straight alignment manifested as slight waviness..$^{37,42}$ Since the average fibre length in sugar palm fibre bundle is evaluated at about 100 to $200 \mathrm{~mm}$, of which exceeds considerably the fibres' stress transfer length, a relatively uniform planar arrangement of fibres in the mat may be present. It is seen that the composites' tensile modulus is slightly but consistently over-predicted at loadings below $30 \mathrm{wt} \%$. This is likely due to the presence of fibre curvature in the mat (as seen in Figure 1(a)) making the composite somewhat wavier. 


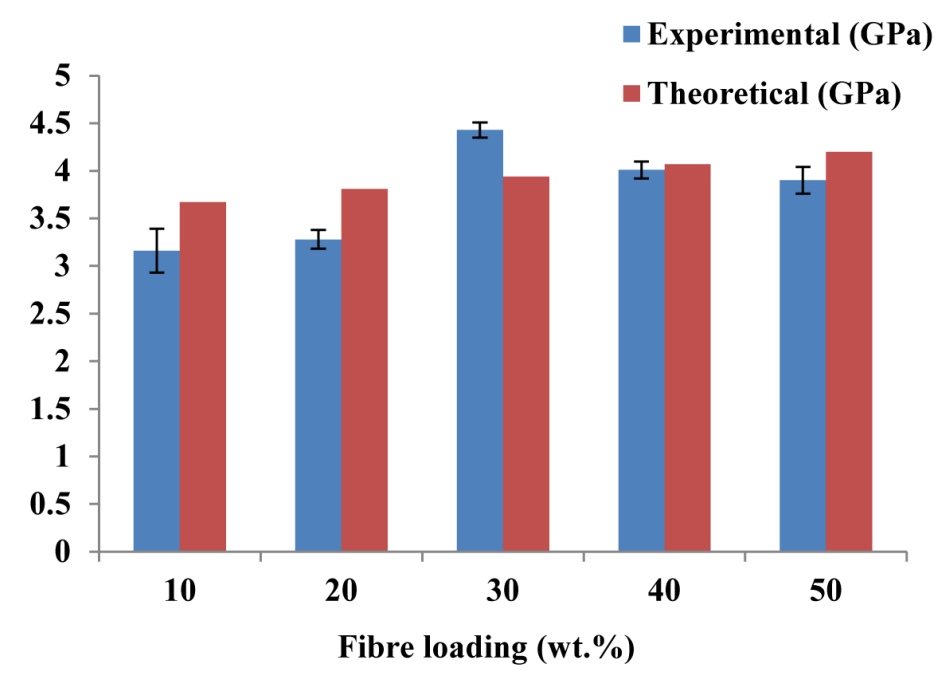

Figure 3: Comparison of tensile modulus form experimental value and theoretical value from Rules of Mixture (ROM).

Furthermore, it can be observed from the theoretical values, as calculated using the rule of mixtures formulation, that the modulus values increase as the fibre wt $\%$ loading increases, compared to their experimental value which should decrease after $40 \mathrm{wt} \%$ fibre loading. Research done by Aziz et al., and Sreekala et al., has shown that at very high fibre loadings, processing is difficult with their compatibility becoming very poor, which may be the reason for the decrementation of its properties. ${ }^{37,47}$ At higher fibre loading, the fibre entanglement possibility increases as the fibre orientation uniformity decreases; fibres having the layering out possibility due to decreased interlaminar bonding. Further packing defects may occur, which may reduce the stress transfer effectiveness from matrix to the fibres. It has also been noted that especially for compression moulding process, squeezing flow causes some transverse fibre orientation in the surface area. This is a decisive factor in the composites' mechanical performance.

\subsubsection{Flexural properties}

For flexural loading tests, the composite samples were subject to compression, tension and shear stress. In a three-point flexural test, the failures occurred due to bending and shearing actions. According to Abdul Khalil et al., in general, the flexural properties will initially decrease to a certain amount of fibre, before reposting a reversal. ${ }^{41}$ Figure 4 shows the flexural strength and modulus of untreated and treated sugar palm fibre yarn reinforced polyester composites. 
From the obtained results, increases in fibre loading up to $30 \mathrm{wt} \%$ produce a corresponding flexural strength and modulus value increase compared with fibre loading from 10 to $50 \mathrm{wt} \%$. However, the flexural properties of composites declined after $40 \mathrm{wt} \%$ fibre content. This flexural property decreases at higher fibre loadings ( $>40 \mathrm{wt} \%)$ due to increased fibre-fibre interactions and the insufficiency of the matrix to penetrate and coat the fibres, which results in a low-stress transfer mechanism..$^{48,49}$ Meanwhile, flexural property enhancement with increased fibre loading was due to the fact that the composites are able to withstand more loads with corresponding fibres population increase in the composite. Fibre presence in sufficient amounts can establish an effective stress transfer within the matrix, due to the inherent properties of sugar palm yarn. Besides, the fibre orientation in the specimen also has a significant effect on the results. According to Aziz et al., flexural strength greatly depends on fibre orientation and alignment and the location of resin-rich areas. ${ }^{47}$ However, long fibres tend to give better strength than short fibres due to their good orientation parallel to applied load.

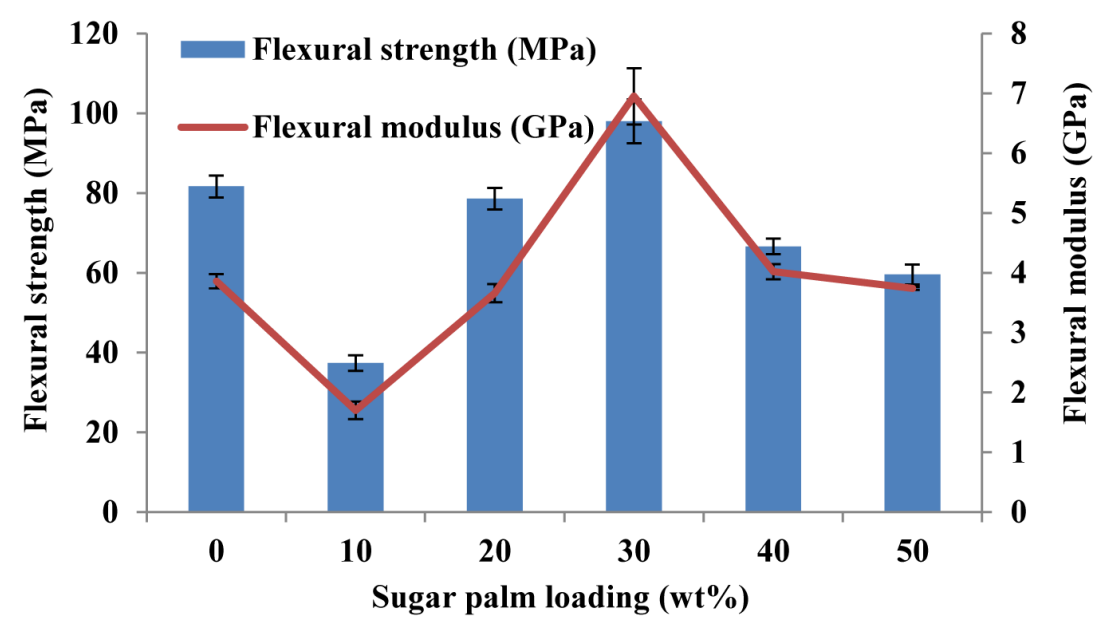

Figure 4: Effect of sugar palm fibre yarn loading on flexural properties.

\subsubsection{Impact properties}

Impact strength is defined as the ability of the material in resisting fractures under high speed applied stress, and the related energy required to break said specimens. This is related to the materials' inherent toughness, which is influenced by respective built-in interfacial bonding strength and the fibre itself. ${ }^{50}$

The effects of sugar palm yarn on the reinforced unsaturated polyester composites' impact strength at various fibre loadings are shown in Figure 5. As depicted in Figure 5, impact strength increased moderately at $1100 \%$ with the incorporation of 
$10 \mathrm{wt} \%$ sugar palm fibre yarn. With a yarn fibre loading increase from $10 \mathrm{wt} \%$ to $40 \mathrm{wt} \%$, the composites' impact strength also increased, which may be attributed to the improved toughness offered by the sugar palm fibre yarn in the composites. ${ }^{51}$ The impact strength increased with further sugar palm fibre increases beyond the $10 \mathrm{wt} \%$ level. The sugar palm fibre bundles' alignment in parallel the direction of the impact force may help absorb the impact force imparted to the test samples. Enhanced impact strength was shown for higher sugar palm fibre filling levels beyond $10 \mathrm{wt} \%$ up to $40 \mathrm{wt} \%$ loading. At $50 \mathrm{wt} \%$ loading, the sugar palm fibre clustering effect in the composite took over.

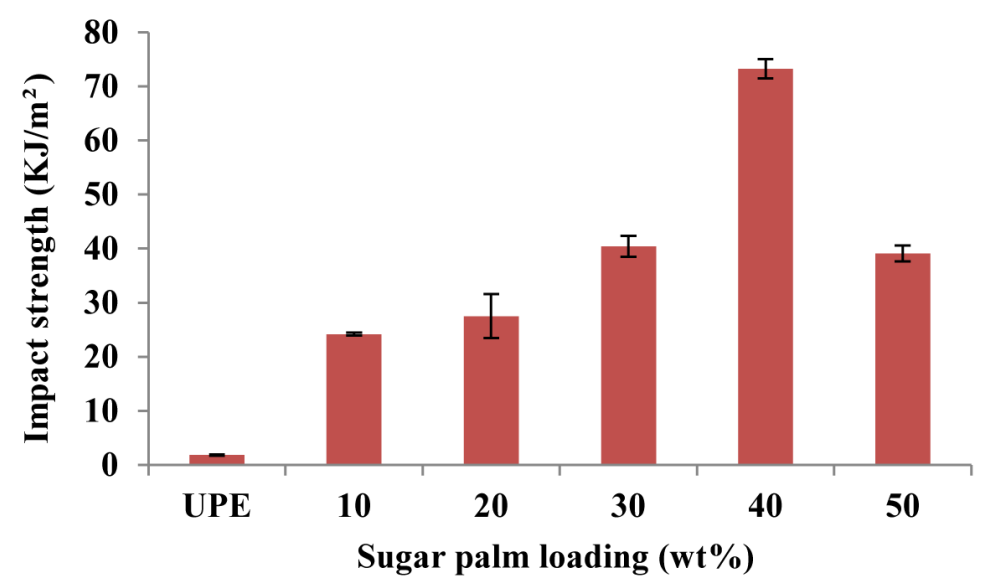

Figure 5: Effect of yarn sugar palm loading on impact strength.

An amount of $40 \mathrm{wt} \%$ loading composites demonstrated the highest impact properties among the set tested. According to Khalil et al., these values are contributed to by the sufficient presence of fibres in the composite. ${ }^{41}$ These fibres provided an effective stress transfer between the fibres and the matrix. Excellent wettability of the fibres also occurred with this composition. A tremendous impact strength increase was reported at $40 \mathrm{wt} \%$ yarn loading, which may be contributed to by the pack arrangement of sugar palm fibre yarn within the composites. This arrangement contributed to an effective load transference between the matrix and fibre when the composite is subject to a high-speed impact load.

However, composites with fibre loading over $40 \mathrm{wt} \%$ exhibited some reduction of impact properties. This is due to increases in fibre-fibre interaction and decreased effectiveness of stress transfer between the fibre and matrix. This contributes to the impact properties decrease at higher fibre loadings. According to Aziz et al., in addition to the commonly practiced surface treatment for improving fibre-matrix bond, the toughness of composites may be improved by reducing the friction stress between the fibre and matrix at a fibre critical length. ${ }^{47}$ 


\subsection{Thermal Characterisations}

\subsubsection{Thermogravimetric analysis}

TGA analysis was carried out to observe the distinct process of the fibre's weight loss at different temperatures. Figure 6(a) shows there are three stages of weight loss process within a prolonged temperature ranges. From the curve, there is a small noticeable step in the first stage of weight loss. The first occurrence was at the temperature range of $30^{\circ} \mathrm{C}$ to $110^{\circ} \mathrm{C}$ (Figure 6 (a)). This is due to the release of the fibre's moisture content. A major decomposition occurs at the second stage with the temperature range of $150^{\circ} \mathrm{C}$ to $380^{\circ} \mathrm{C}$ (Figures $6(\mathrm{a})$ and (b)). This is due to the decomposition of the three major constituents of natural fibres, which are hemicellulose, cellulose and lignin. A single degradation step was observed for neat UPE by statistical chain rupture, in which styrene is the primary product at the range of $360^{\circ} \mathrm{C}$ to $400^{\circ} \mathrm{C}$ (Figure $\left.6(\mathrm{~b})\right)^{52}$

According to Sahari et al., the decomposition of natural fibres generally consists of four stages..$^{25}$ The first stage is the decomposition of hemicellulose, followed by cellulose, lignin and finally, the ash. Hemicelluloses often decompose at $220^{\circ} \mathrm{C}$, which substantially completes at $315^{\circ} \mathrm{C}$. The decomposition of cellulose takes place as the second stage of decomposition. Due to the highly crystalline nature of cellulose, it is relatively thermally stable. Cellulose itself has crystalline and amorphous parts. The amorphous part will degrade earlier than the crystalline part, which has higher thermal stability, as shown as a multi-step in the second main decomposition stage as visualised in the DTG curve. Lignin shows peaks in DTG below $200^{\circ} \mathrm{C}$ (Figure 6(b)). Between $200^{\circ} \mathrm{C}$ and $320^{\circ} \mathrm{C}$ (Figure 6(b)), there are two distinct peaks which show hemicellulose and cellulose components decomposition. Highly crystalline cellulose starts to decompose until hemicellulose had completely decomposed; which normally starts at higher temperature, about $320^{\circ} \mathrm{C}$. Further down the line is the decomposition of lignin. Lignin's molecular structure is mostly composed of aromatic rings. Its various branching and relevant present chemical bonds lead to a wide range of decomposition temperatures. ${ }^{53}$ It is more difficult to decompose compared to hemicellulose and cellulose. The decomposition of lignin starts at a temperature as early as $160^{\circ} \mathrm{C}$ and it decomposes slowly. Lignin extends its decomposition temperature as high as $900^{\circ} \mathrm{C}$ in order to complete this process. ${ }^{.4}$ The prolonged decomposition is due to lignin being a very tough component. Accordingly, it is known as the compound that gives rigidity to plant materials. Finally, once the lignin has completely decomposed, the component left is the inorganic ash material (not unlike silica). This inorganic material only decomposes at the very high temperature of $1730^{\circ} \mathrm{C} \cdot{ }^{25}$ 

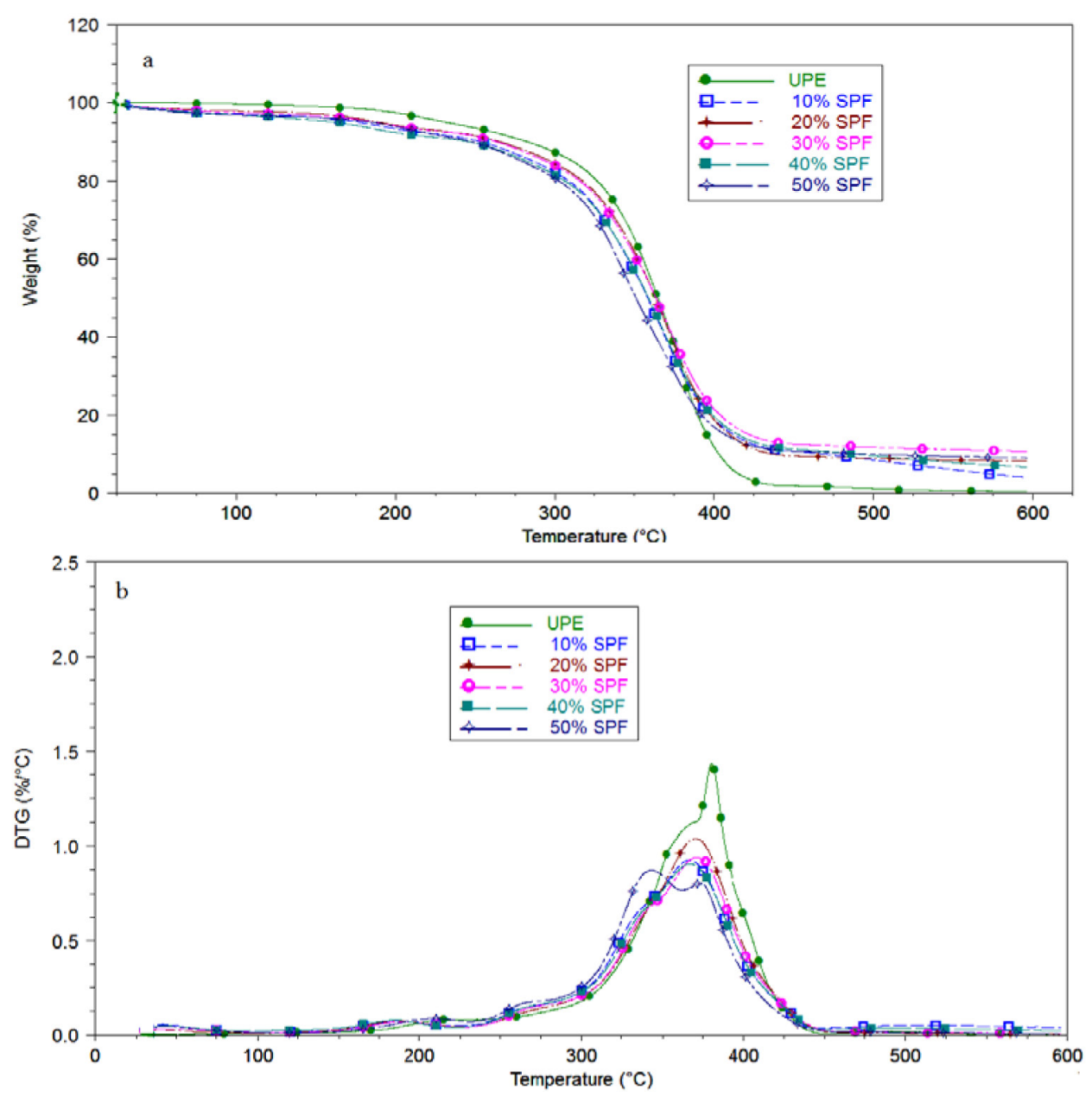

Figure 6: Effect of yarn loading on thermal properties: TGA curve (a) and DTG curve (b).

From the result obtained in Table 4, it may be concluded that the sugar palm fibres addition to the composite decreases the UPE degradation onset occurring temperature, and the maximum thermal decomposition. This occurs due to some portions of the UPE matrix being replaced with the less thermally stable sugar palm fibres, which then reduces the thermal stability of the polymer matrix system as a whole..$^{55}$ The tremendous thermal stability decreases upon the sugar palm fibres increases is also contributed to by fibres-fibres interaction. This particular fibre-fibre interaction is stronger at higher sugar palm fibres loadings than that of fibres-UPE interaction; this may further reduce the decomposition temperature due to non-limited mobility. ${ }^{56}$ 
Table 4: Characteristic temperature at elevated weight loss.

\begin{tabular}{cccccc}
\hline Yarn sugar palm loading $(\mathrm{wt} \%)$ & $\mathrm{T}_{\text {onset }}\left({ }^{\circ} \mathrm{C}\right)$ & $\mathrm{T}_{\max }\left({ }^{\circ} \mathrm{C}\right)$ & $\mathrm{T}_{\text {end }}\left({ }^{\circ} \mathrm{C}\right)$ & $\mathrm{T}_{10 \%}\left({ }^{\circ} \mathrm{C}\right)$ & Residue (\%) \\
\hline 0 & 340.53 & 380.42 & 593.00 & 282.90 & 0.42 \\
10 & 307.79 & 366.74 & 595.59 & 253.85 & 4.03 \\
20 & 301.48 & 370.30 & 595.22 & 265.62 & 6.75 \\
30 & 301.50 & 370.96 & 596.01 & 263.86 & 8.28 \\
40 & 295.91 & 366.84 & 595.36 & 246.48 & 9.07 \\
50 & 294.88 & 343.04 & 595.59 & 248.05 & 10.78 \\
\hline
\end{tabular}

It is clearly shown that the increase in fibre hence increases the residue content percentage as compared to neat UPE. The formation of residue provides a barrier between the heat source and polymeric material, subsequently slowing down or inhibiting the out-diffusion of volatile decomposition products from the composites. ${ }^{57}$ Thus, by increasing the sugar palm loading, the char residue increases and forms a thicker barrier/layer between the heat source and polymeric material. This thicker barrier of char residue thus result in the higher temperatures required for the composites' decomposition. Therefore, the thermal stability of the composites increases with the sugar palm loading increase. ${ }^{45}$

\section{CONCLUSION}

The density of the composites decreases with the increase in sugar palm yarn loadings, due to lower density of sugar palm fibres which is $1.053 \mathrm{~g} \mathrm{~cm}^{-3}$ as compared to the cured density of unsaturated polyester composites, which is $1.212 \mathrm{~g} \mathrm{~cm}^{-3}$. Theoretical void calculations indicate that $30 \mathrm{wt} \%$ to $50 \mathrm{wt} \%$ of fibre loading exhibits voids as compared to the 0,10 and $20 \mathrm{wt} \%$ fibre loadings. Similar increasing trends in the performance of tensile strength, tensile modulus, flexural strength and flexural modulus were shown in sugar palm yarn loadings of up to $30 \mathrm{wt} \%$. However, maximum impact strength is achieved at $40 \mathrm{wt} \%$ of sugar palm fibre yarn loadings. Elongation at break increases with the increment of sugar palm yarn loading up to $50 \mathrm{wt} \%$. The different values obtained from the ROM demonstrate how several key parameters which must be taken into account during composite processing in order to achieve the desired performance. The thermal stability of the composite decreases in accordance with onset and maximum temperatures, while the percentage of residue increases for higher fibre loadings. 


\section{ACKNOWLEDGEMENTS}

The authors wish to thank Universiti Putra Malaysia (UPM) for providing research grants (GP-IPB), project number GP-IPB/2014/9441502 and excellent facilities. Appreciation is also extended to Faculty of Applied Sciences (FSG), Universiti Teknologi MARA (UiTM) Shah Alam, Malaysia for excellent facilities and cooperation.

\section{REFERENCES}

1. Faruk, O. et al. (2012). Biocomposites reinforced with natural fibers: 20002010. Progr. Polym. Sci., 37(11), 1552-1596, https://doi.org/10.1016/j. progpolymsci.2012.04.003.

2. Koronis, G., Silva, A. \& Fontul, M. (2013). Green composites: A review of adequate materials for automotive applications. Compos. B Eng., 44(1), 120-127, https://doi.org/10.1016/j.compositesb.2012.07.004.

3. Vilay, V. et al. (2008). Effect of fiber surface treatment and fiber loading on the properties of bagasse fiber-reinforced unsaturated polyester composites. Compos. Sci. Technol., 68(3-4), 631-638, https://doi.org/10.1016/j. compscitech.2007.10.005.

4. Ishak, M. R. et al. (2013). Sugar palm (Arenga pinnata): Its fibres, polymers and composites. Carbohydr. Polym., 91(2), 699-710. https://doi. org/10.1016/j.carbpol.2012.07.073.

5. Bachtiar, D., Sapuan, S. M. \& Hamdan, M. M. (2008). The effect of alkaline treatment on tensile properties of sugar palm fibre reinforced epoxy composites. Mater. Des., 29(7), 1285-1290, https://doi.org/10.1016/j. matdes.2007.09.006.

6. Rokbi, M. et al. (2011). Effect of chemical treatment on flexure properties of natural fiber-reinforced polyester composite. Proced. Eng., 10, 2092-2097, https://doi.org/10.1016/j.proeng.2011.04.346.

7. Dhakal, H. N., Zhang, Z. Y. \& Richardson, M. O. W. (2007). Effect of water absorption on the mechanical properties of hemp fibre reinforced unsaturated polyester composites. Compos. Sci. Technol., 67(7), 1674-1683, https://doi. org/10.1016/j.compscitech.2006.06.019.

8. Ishak, M. R. et al. (2011). Effects of impregnation pressure on physical and tensile properties of impregnated sugar palm (Arengga pinnata) fibres. Key Eng. Mater., 471-472, 1153-1158, https://doi.org/10.4028/www. scientific.net/KEM.471-472.1153. 
9. Ishak, M. R. et al. (2011). Effects on impregnation time on physical and tensile properties of impregnated sugar palm (Arengga pinnata) fibres. Key Eng. Mater., 471-472, 1147-1152, https://doi.org/10.4028/www. scientific.net/KEM.471-472.1147.

10. Suwartapradja, O. S. (2003). Arenga pinnata: A case study of indigenous knowledge on the utilization of a wild food plant in West Java. Unpublished paper.

11. Ishak, M. R. et al. (2011). Characterization of sugar palm (Arenga pinnata) fibres. J. Therm. Anal. Calorim., 109(2), 981-989, https://doi.org/10.1007/ s10973-011-1785-1.

12. Wahjono, A. (2009). Pengaruh penambahan serat ijuk pada kuat tarik campuran semen-pasir dan kemungkinan aplikasinya. Jur. Tek. Sip. Univ. Atma Jaya Yogya., 8(2), 159-169.

13. Bachtiar, D., Sapuan, S. M. \& Hamdan, M. M. (2010). Flexural properties of alkaline treated sugar palm fibre reinforced epoxy composites. Int. J. Autom. Mech. Eng., 1, 79-90.

14. Bachtiar, D. et al. (2010). The tensile properties of single sugar palm (Arenga pinnata) fibre. Paper presented at the IOP Conference Series: Materials Science and Engineering, 11(2010), 012012, https://doi.org/10.1088/1757899X/11/1/012012.

15. Bachtiar, D., Sapuan, S. M. \& Hamdan, M. M. (2009). The influence of alkaline surface fibre treatment on the impact properties of sugar palm fibrereinforced epoxy composites. Polym.-Plast. Technol. Eng., 48(4), 379-383, https://doi.org/10.1080/03602550902725373.

16. Khudhur, P. A. et al. (2013). Fracture toughness of sugar palm fiber reinforced epoxy composites. Int. J. Sci. Res. (IJSR), 2(12), 273-279.

17. Leman, Z. et al. (2008). Moisture absorption behavior of sugar palm fiber reinforced epoxy composites. Mater. Des., 29(8), 1666-1670, https://doi. org/10.1016/j.matdes.2007.11.004.

18. Leman, Z. et al. (2008). The effect of environmental treatments on fiber surface properties and tensile strength of sugar palm fiber-reinforced epoxy composites. Polym.-Plast. Technol. Eng., 47(6), 606-612, https://doi. org/10.1080/03602550802059451.

19. Leman, Z., Sapuan, S. M. \& Ahmad, M. M. H. M. (2008). Low cost natural methods of improving the interfacial adhesion of sugar palm fibre reinforced epoxy composites. Paper presented at the Proceding of Postgraduate Seminar on Natural Fibre Composites, 33-48.

20. Misri, S. et al. (2010). Mechanical properties and fabrication of small boat using woven glass/sugar palm fibres reinforced unsaturated polyester hybrid composite. IOP Conf. Series Mater. Sci. Eng., 11, 012015. https://doi.org/ 10.1088/1757-899x/11/1/012015. 
21. Sahari, J. et al. (2012). Physical and chemical properties of different morphological parts of sugar palm fibres. Fib. Text. East. Eur., 20, 21-24.

22. Sahari, J. et al. (2013). Thermo-mechanical behaviors of thermoplastic starch derived from sugar palm tree (Arenga pinnata). Carbohydr. Polym., 92(2), 1711-1716. https://doi.org/10.1016/j.carbpol.2012.11.031.

23. Sahari, J. et al. (2011). Comparative study of physical properties based on different parts of sugar palm fibre reinforced unsaturated polyester composites. Key Eng. Mater., 471-472, 455-460, https://doi.org/10.4028/ www.scientific.net/KEM.471-472.455.

24. Sahari, J., Sapuan, S. M., Ismarrubie, Z. N. \& Rahman, M. Z. A. (2012). Tensile and impact properties of different morphological parts of sugar palm fibre-reinforced unsaturated polyester composites. Polym. Polym. Compos., 20(9, 2012), 861-866.

25. Sahari, J. et al. (2013). Mechanical and thermal properties of environmentally friendly composites derived from sugar palm tree. Mater. Des., 49, 285-289, https://doi.org/10.1016/j.matdes.2013.01.048.

26. Sapuan, S. M. \& Bachtiar, D. (2012). Mechanical properties of sugar palm fibre reinforced high impact polystyrene composites. Proc. Chem., 4, 101106, https://doi. 10.1016/j.proche.2012.06.015.

27. Shalwan, A. \& Yousif, B. F. (2013). In state of art: Mechanical and tribological behaviour of polymeric composites based on natural fibres. Mater. Des., 48, 14-24, https://doi.org/10.1016/j.matdes.2012.07.014.

28. Mei-po, H. et al. (2012). Critical factors on manufacturing processes of natural fibre composites. Compos. B Eng., 43(8), 3549-3562.

29. Brahim, S. B. \& Cheikh, R. B. (2007). Influence of fibre orientation and volume fraction on the tensile properties of unidirectional Alfa-polyester composite. Compos. Sci. Technol., 67(1), 140-147, https://doi.org/10.1016/j. compscitech.2005.10.006.

30. Pan, N. (1993). Prediction of statistical strengths of twisted fibre structures. J. Mater. Sci., 28(22), 6107-6114, https://doi.org/10.1007/BF00365030.

31. Monego, C. J. \& Backer, S. (1968). Tensile rupture of blended yams. Text. Res. J., 38(7), 762-766, https://doi.org/10.1177/004051756803800712.

32. Pan, N. (1992). Development of a constitutive theory for short fiber yarns: Mechanics of staple yarn without slippage effect. Text. Res. J., 62(12), 749-765, https://doi.org/10.1177/004051759206201208.

33. George, G. et al. (2010). Recent advances in green composites. Key Eng. Mater., 425, 107-166, https://doi.org/10.4028/www.scientific.net/ KEM.425.107.

34. Venkateshwaran, N., Elayaperumal, A. \& Sathiya, G. K. (2012). Prediction of tensile properties of hybrid-natural fiber composites. Compos. B Eng., 43(2), 793-796, https://doi.org/10.1016/j.compositesb.2011.08.023. 
35. Ku, H., Wang, H., Pattarachaiyakoop, N. \& Trada, M. (2011). A review on the tensile properties of natural fiber reinforced polymer composites. Compos. B Eng., 42(4), 856-873, https://doi.org/10.1016/j.compositesb.2011.01.010.

36. Lei, W., Lei, W. G. \& Ren, C. (2006). Effect of volume fraction of ramie cloth on physical and mechanical properties of ramie cloth/UP resin composite. Trans. Nonferr. Met. Soc. Ch., 16, s474-s477, https://doi.org/10.1016/j. compositesb.2011.01.010.

37. Sreekala, M. S. et al. (2002). The mechanical performance of hybrid phenolformaldehyde-based composites reinforced with glass and oil palm fibres. Compos. Sci. Technol., 62(3), 339-353, https://doi.org10.1016/S02663538(01)00219-6.

38. Vaxman, A., Narkis, M., Siegmann, A. \& Kenig, S. (1989). Short-fiberreinforced thermoplastics. Part III: Effect of fiber length on rheological properties and fiber orientation. Polym. Compos., 10(6), 454-462, https://doi.org/10.1002/pc.750100610.

39. Hristov, V. et al. (2004). Deformation mechanisms and mechanical properties of modified polypropylene/wood fiber composites. Polym. Compos., 25(5), 521-526, https://doi.org10.1002/pc.20045.

40. Bakare, I. O. et al. (2010). Mechanical and thermal properties of sisal fiberreinforced rubber seed oil-based polyurethane composites. Mater. Des., 31(9), 4274-4280, https://doi.org/10.1016/j.matdes.2010.04.013.

41. Abdul Khalil, H. P. S. et al. (2007). Agro-hybrid composite: The effects on mechanical and physical properties of oil palm fiber (EFB)/glass hybrid reinforced polyester composites. J. Reinf. Plast. Compos., 26(2), 203-218, https://doi.org/10.1177/0731684407070027.

42. Sreekumar, P. et al. (2007). A comparative study on mechanical properties of sisal-leaf fibre-reinforced polyester composites prepared by resin transfer and compression moulding techniques. Compos. Sci. Technol., 67(3), 453461, https://doi.org/10.1016/j.compscitech.2006.08.025.

43. Ismail, H. et al. (2008). Morphological, thermal and tensile properties of halloysite nanotubes filled ethylene propylene diene monomer (EPDM) nanocomposites. Polym. Test., 27(7), 841-850, https://doi.org/10.1016/j. polymertesting.2008.06.007.

44. Supri, A. G. \& Ismail, H. (2011). The effect of isophorone diisocyanatepolyhydroxyl groups modified water hyacinth fibers (Eichhornia crassiper) on properties of low density polyethylene/acrylonitrile butadiene styrene (LDPE/ABS) composites. Polym.-Plast. Technol. Eng., 50(2), 113-120, https://doi.org/10.1080/03602559.2010.531428. 
45. Pang, A. L., Ismail, H. \& Abu Bakar, A. (2015). Effects of kenaf loading on processability and properties of linear low-density polyethylene/poly (vinyl alcohol)/kenaf composites. BioResour., 10(4), https://doi.org/10.15376/ biores. 10.4.7302-7314.

46. Norizan, M. N. et al. (2017). A review: Fibres, polymer matrices and composites. Pertanika J. Sci. Technol., 25(4), 1085-1102.

47. Aziz, S. H. \& Ansell, M. P. (2004). The effect of alkalization and fibre alignment on the mechanical and thermal properties of kenaf and hemp bast fibre composites: Part 1 - Polyester resin matrix. Compos. Sci. Technol., 64(9), 1219-1230. https://doi.org/10.1016/j.compscitech.2003.10.001

48. Devi, L. U., Bhagawan, S. S. \& Thomas, S. (1997). Mechanical properties of pineapple leaf fiber-reinforced polyester composites. J. Appl. Polym. Sci., 64(9), 1739-1748.

49. Arib, R. M. N. et al. (2006). Mechanical properties of pineapple leaf fibre reinforced polypropylene composites. Mater. Des., 27(5), 391-396, https://doi.org/10.1016/j.matdes.2004.11.009.

50. Wambua, P., Ivens, J. \& Verpoest, I. (2003). Natural fibres: Can they replace glass in fibre reinforced plastics? Compos. Sci. Technol., 63(9), 1259-1264, https://doi.org/10.1016/S0266-3538(03)00096-4.

51. Reddy, G. V., Naidu, S. V. \& Rani, T. S. (2008). Impact properties of kapok based unsaturated polyester hybrid composites. J. Reinf. Plast. Comp., 27(16-17), 1789-1804, https://doi.org/10.1177/0731684407087380.

52. Manfredi, L. B., Rodríguez, E. S., Wladyka-Przybylak, M. \& Vázquez, A. (2006). Thermal degradation and fire resistance of unsaturated polyester, modified acrylic resins and their composites with natural fibres. Polym. Degrad. Stab., 91(2), 255-261, https://doi.org/10.1016/j. polymdegradstab.2005.05.003.

53. Watkins, D. et al. (2015). Extraction and characterization of lignin from different biomass resources. J. Mater. Res. Technol., 4(1), 26-32, https://doi. org/10.1016/j.jmrt.2014.10.009.

54. Yang, H. et al. (2007). Characteristics of hemicellulose, cellulose and lignin pyrolysis. Fuel, 86(12), 1781-1788, https://doi.org/10.1016/j. fuel.2006.12.013.

55. Yussuf, A. A., Massoumi, I. \& Hassan, A. (2010). Comparison of polylactic $\mathrm{acid} / \mathrm{kenaf}$ and polylactic acid/rise husk composites: The influence of the natural fibers on the mechanical, thermal and biodegradability properties. J. Polym. Environ., 18(3), 422-429, https://doi.org/10.1007/s10924-0100185-0.

56. Zhou, Y. M. et al. (2012). Effect of nanocellulose isolation techniques on the formation of reinforced poly (vinylalcohol) nanocomposite films. Exp. Polym. Lett., 6(10), 794-804, https://doi.org/10.3144/expresspolymlett.2012.85. 
57. Ismail, H., Abdullah, A. H. \& Bakar, A. A. (2010). Kenaf core reinforced high-density polyethylene/soya powder composites: The effects of filler loading and compatibilizer. J. Reinf. Plast. Compos., 29(16), 2489-2497, https://doi.org/10.1177/0731684409354392. 